\title{
Tonic Enhancement of Endocannabinoid-Mediated Retrograde Suppression of Inhibition by Cholinergic Interneuron Activity in the Striatum
}

\author{
Madoka Narushima, ${ }^{1,2,3}$ Motokazu Uchigashima, ${ }^{4}$ Masahiro Fukaya, ${ }^{4}$ Minoru Matsui, ${ }^{5}$ Toshiya Manabe, ${ }^{3,5}$ \\ Kouichi Hashimoto, ${ }^{1,3}$ Masahiko Watanabe, ${ }^{4}$ and Masanobu Kano ${ }^{1,2}$ \\ ${ }^{1}$ Department of Cellular Neuroscience, Osaka University, Graduate School of Medicine, Yamada-oka, Suita 565-0871, Japan, ${ }^{2}$ Department of Cellular \\ Neurophysiology, Graduate School of Medical Science, Kanazawa University, Takara-machi, Kanazawa 920-8640, Japan, ${ }^{3}$ Core Research for Evolutional \\ Science and Technology, Japan Science and Technology Agency, Tokyo 102-8666, Japan, ${ }^{4}$ Department of Anatomy, Hokkaido University School of \\ Medicine, Sapporo 060-8638, Japan, and 5Division of Neuronal Network, Department of Basic Medical Sciences, Institute of Medical Science, University of \\ Tokyo, Tokyo 108-8639, Japan
}

Tonically active cholinergic interneurons in the striatum modulate activities of striatal outputs from medium spiny (MS) neurons and significantly influence overall functions of the basal ganglia. Cellular mechanisms of this modulation are not fully understood. Here we show that ambient acetylcholine (ACh) derived from tonically active cholinergic interneurons constitutively upregulates depolarizationinduced release of endocannabinoids from MS neurons. The released endocannabinoids cause transient suppression of inhibitory synaptic inputs to MS neurons through acting retrogradely onto presynaptic $\mathrm{CB}_{1}$ cannabinoid receptors. The effects were mediated by postsynaptic $M_{1}$ subtype of muscarinic ACh receptors, because the action of a muscarinic agonist to release endocannabinoids and the enhancement of depolarization-induced endocannabinoid release by ambient ACh were both deficient in $M_{1}$ knock-out mice and were blocked by postsynaptic infusion of guanosine-5'-O-(2-thiodiphosphate). Suppression of spontaneous firings of cholinergic interneurons by inhibiting $I_{\mathrm{h}}$ current reduced the depolarization-induced release of endocannabinoids. Conversely, elevation of ambient ACh concentration by inhibiting choline esterase significantly enhanced the endocannabinoid release. Paired recording from a cholinergic interneuron and an MS neuron revealed that the activity of single cholinergic neuron could influence endocannabinoid-mediated signaling in neighboring MS neurons. These results clearly indicate that striatal endocannabinoid-mediated modulation is under the control of cholinergic interneuron activity. By immunofluorescent and immunoelectron microscopic examinations, we demonstrated that $\mathrm{M}_{1}$ receptor was densely distributed in perikarya and dendrites of dopamine $\mathrm{D}_{1}$ or $\mathrm{D}_{2}$ receptor-positive MS neurons. Thus, we have disclosed a novel mechanism by which the muscarinic system regulates striatal output and may contribute to motor control.

Key words: $\mathrm{CB}_{1}$ receptor; acetylcholine; muscarinic receptor; DSI; medium spiny neuron; basal ganglia

\section{Introduction}

The striatum is the main input structure of the basal ganglia that subserves motor and cognitive functions (Wilson, 2004). The medium spiny (MS) neurons are the projection neurons from the striatum that constitute $95 \%$ of whole striatal neuronal population (Wilson, 2004). In contrast, cholinergic interneurons constitute only $<2 \%$ of total striatal neurons, but they have widespread axonal projections and exhibit tonic firings and, therefore, can significantly influence activities of striatal neurons (Calabresi et al., 2000). Cholinergic system is known to contribute to various

Received 0ct. 26, 2006; revised Nov. 28, 2006; accepted Nov. 29, 2006.

This work was supported by Ministry of Education, Culture, Sports, Science, and Technology of Japan Grants-in Aid for Scientific Research 17023021 and 17100004 (M.K.), 16067101 (M.M.), 17023001 (M.W.), and 17023011 (T.M.) and the Toyota Riken Foundation (M.K.). M.N. was a recipient of Japan Society for the Promotion of Science Research Fellowship for Young Scientists Grant 16-54131. We thank T. Ohno-Shosaku and T. Tabata for valuable comments and $\mathrm{S}$. Kusakawa for technical assistance.

Correspondence should be addressed to Masanobu Kano, Department of Cellular Neuroscience, Graduate School of Medicine, Osaka University, Suita 565-0871, Japan. E-mail: mkano@cns.med.osaka-u.ac.jp.

DOI:10.1523/JNEUROSCI.4644-06.2007

Copyright $\odot 2007$ Society for Neuroscience $\quad$ 0270-6474/07/270496-11\$15.00/0 striatal functions, including control of motor activity (Kaneko et al., 2000), achievement of goal-directed behavior (Apicella, 2002), and synaptic plasticity (Calabresi et al., 2000; Wang et al., 2006). Effects of acetylcholine (ACh) are mediated by ionotropic and/or metabotropic (muscarinic) receptors. Muscarinic ACh receptors (mAChRs) comprise five subtypes, in which $M_{1}, M_{3}$, and $M_{5}$ are coupled to $G_{q / 11}$-protein, activate phospholipase $C \beta$ (PLC $\beta$ ), and produce $\mathrm{IP}_{3}$ and diacylglycerol (DAG), whereas $\mathrm{M}_{2}$ and $\mathrm{M}_{4}$ are coupled to $\mathrm{G}_{\mathrm{i} / \mathrm{o}}$-proteins and inhibit cAMP production (Matsui et al., 2004). MS neurons were shown to possess $M_{1}$ and $\mathrm{M}_{4}$ (Yan et al., 2001), and activation of $\mathrm{mAChRs}$ is known to modulate excitability of MS neurons. $\mathrm{mAChR}$ activation reduces $\mathrm{K}^{+}$and/or $\mathrm{Ca}^{2+}$ conductance (Howe and Surmeier, 1995; Lin et al., 2004; Shen et al., 2005) and postsynaptically enhances NMDA receptor-mediated responses (Calabresi et al., 1998). Moreover, muscarinic agonists presynaptically inhibit both excitatory $(\mathrm{Ca}-$ labresi et al., 2000) and inhibitory (Koos and Tepper, 2002) synaptic inputs onto MS neurons. Thus, ACh can modulate striatal outputs through multiple mechanisms. 
A

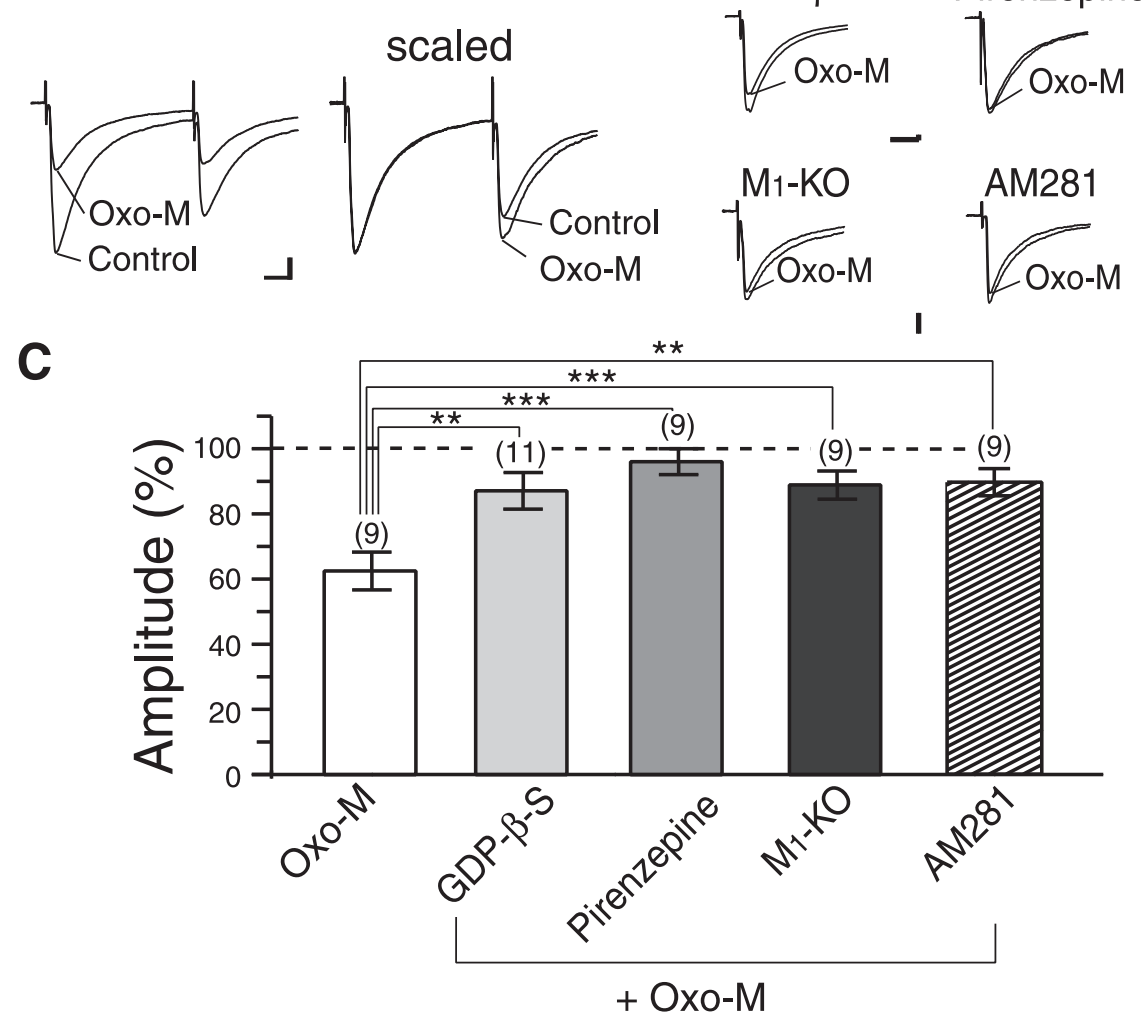

Figure 1. Muscarinic suppression of IPSCs of MS neurons requires postsynaptic $M_{1}$ receptor and endocannabinoid signaling. $\boldsymbol{A}$, Representative result showing the effect of bath applied oxo-M (1 $\mu \mathrm{m})$ on IPSCs of an MS neuron. Left, Sample traces of IPSCS (average of 3 traces) in response to paired stimuli. Traces recorded before and during bath application of $1 \mu \mathrm{M}$ oxo-M are superimposed. Calibration: 100 pA, 10 ms. Right, The amplitude of the first IPSC in oxo-M was scaled to that of control. $\boldsymbol{B}$, Sample data showing the effect of oxo-M on IPSCS of MS neurons with intracellular GDP- $\beta$-S in the presence of pirenzepine from $M_{1}-K 0$ and with preincubation of AM281. IPSC traces recorded before and during bath application of $1 \mu \mathrm{M}$ oxo-M are superimposed. Calibration: 100 pA, 5 ms. C, Summary bar graph showing the effect of $1 \mu \mathrm{m}$ oxo-M alone or with intracellular GDP- $\beta$-S in the presence of pirenzepine from $M_{1}-K 0$ and with preincubation of AM281 on IPSCS. Data are expressed as percentage of IPSC amplitudes in 0x0-M relative to the values in the standard extracellular solution. Numbers of tested cells are indicated in parentheses for this and subsequent figures. ${ }^{* *} p<0.01 ;{ }^{* * *} p<0.001$.

It has been demonstrated in the hippocampus that activation of postsynaptic $M_{1}$ and/or $M_{3}$ receptors triggers release of endocannabinoids from postsynaptic neurons and retrogradely suppresses inhibitory synaptic transmission by activating presynaptic cannabinoid $C_{1}$ receptor $\left(C_{1} R\right.$ ) (Kim et al., 2002; Fukudome et al., 2004). Moreover, $\mathrm{M}_{1}$ and/or $\mathrm{M}_{3}$ activation significantly enhances depolarization-induced suppression of inhibition (DSI) (Kim et al., 2002; Ohno-Shosaku et al., 2003), a phenomenon known to be mediated by endocannabinoids (Ohno-Shosaku et al., 2001; Wilson and Nicoll, 2001). The striatum is a brain structure in which $\mathrm{CB}_{1} \mathrm{R}$ is abundantly expressed (Herkenham et al., 1991; Hohmann and Herkenham, 2000) and inhibitory synaptic responses on MS neurons are sensitive to cannabinoid agonists (Szabo et al., 1998). We recently reported that MS neurons undergo DSI (Narushima et al., 2006b). Because MS neurons are shown to possess $\mathrm{M}_{1}$ and $\mathrm{M}_{4}$ (Yan et al., 2001), these data led us to hypothesize that cholinergic action in the striatum may involve endocannabinoid-mediated retrograde signaling.

We show here that mAChR-dependent suppression of inhibitory transmission onto MS neuron is triggered by activation of postsynaptic $M_{1}$ receptors expressed selectively on their somatodendritic compartments and mediated by retrogradely released endocannabinoids. Importantly, DSI of MS neurons is persistently upregulated by ambient ACh derived from tonically active cholinergic interneurons. By using paired recording techniques, we indicate that activity of single cholinergic interneuron significantly influences endocannabinoid signaling in neighboring MS neurons. These results indicate that striatal endocannabinoid-mediated modulation is under the bidirectional control of cholinergic interneuron activity.

\section{Materials and Methods}

Electrophysiology. All experiments were performed according to the guidelines laid down by the animal welfare committee of Kanazawa University, Hokkaido University, and Osaka University. Coronal brain slices containing the cortex and the striatum (300 $\mu \mathrm{m}$ thick) were prepared from $\mathrm{C} 57 \mathrm{BL} / 6$ mice or $\mathrm{M}_{1}$ receptor knock-out mice (Ohno-Shosaku et al., 2003) aged 15-22 d postnatally as described previously (Narushima et al., 2006a). In brief, mice were decapitated under deep halothane anesthesia, and the brains were cooled in ice-cold, modified external solution containing the following (in $\mathrm{mm}$ ): 120 choline- $\mathrm{Cl}, 2 \mathrm{KCl}, 8$ $\mathrm{MgCl}_{2}, 28 \mathrm{NaHCO}_{3}, 1.25 \mathrm{NaH}_{2} \mathrm{PO}_{4}$, and 20 glucose (bubbling with $95 \% \mathrm{O}_{2}$ and $5 \% \mathrm{CO}_{2}$ ) (Narushima et al., 2006a). Slices were cut with a Leica (Wetzlar, Germany) VT1000S slicer. For recovery, slices were incubated at least $1 \mathrm{~h}$ in normal bathing solution composed of the following (in mM): $125 \mathrm{NaCl}, 2.5 \mathrm{KCl}, 2 \mathrm{CaCl}_{2}, 1$ $\mathrm{MgSO}_{4}, 1.25 \mathrm{NaH}_{2} \mathrm{PO}_{4}, 26 \mathrm{NaHCO}_{3}$, and 20 glucose, $\mathrm{pH} 7.4$ (bubbled continuously with a mixture of $95 \% \mathrm{O}_{2}$ and $5 \% \mathrm{CO}_{2}$ at room temperature).

Whole-cell recordings were made from MS neurons in the dorsolateral region of the striatum, using an upright microscope (BX50WI Olympus Optical, Tokyo, Japan) equipped with an infrared CCD camera system (Hamamatsu Photonics, Hamamatsu, Japan). MS neurons were identified visually by their medium-sized, spherical somata as well as their electrophysiological properties (Kita et al., 1984). Resistance of the patch pipette was $3-5 \mathrm{M} \Omega$ when filled with the standard intracellular solution composed of the following (in $\mathrm{mM}$ ): $50 \mathrm{KCl}, 90 \mathrm{~K}$-gluconate, 10 HEPES, 1 EGTA, $0.1 \mathrm{CaCl}_{2}, 4.6 \mathrm{MgCl}_{2}, 4 \mathrm{Na}$-ATP, and 0.4 Na-GTP, pH 7.2, adjusted with $\mathrm{KOH}$. In experiments with ZD7288 (4ethylphenylamino-1,2-dimethyl-6-methylaminopyrimidinium chloride), we used a $\mathrm{Cs}^{+}$-based intracellular solution that was composed of the following (in mM): $50 \mathrm{CsCl}$, 90 Cs-gluconate, 10 HEPES, 1 EGTA, 0.1 $\mathrm{CaCl}_{2}, 4.6 \mathrm{MgCl}_{2}, 4 \mathrm{Na}-\mathrm{ATP}$, and 0.4 Na-GTP, pH 7.2, adjusted with $\mathrm{CsOH}$. In experiments for recording spontaneous IPSCs (sIPSCs), we also used a $\mathrm{Cs}^{+}$-based intracellular solution that was composed of the following (in mM): $140 \mathrm{CsCl}, 10 \mathrm{HEPES}, 1 \mathrm{EGTA}, 0.1 \mathrm{CaCl}_{2}, 4.6 \mathrm{MgCl}_{2}$, $4 \mathrm{Na}-\mathrm{ATP}$, and $0.4 \mathrm{Na}-\mathrm{GTP}, \mathrm{pH} 7.2$, adjusted with $\mathrm{CsOH}$. The pipette access resistance was compensated by $20-50 \%$. MS neurons were usually held at a membrane potential of $-80 \mathrm{mV}$. The bath solution was supplemented with $10 \quad \mu \mathrm{M}$ 2,3-dioxo-6-nitro-1,2,3,4-tetrahydrobenzo quinoxaline-7-sulfonamide and $5 \mu \mathrm{M}(R)$-3-(2-carboxypiperazin-4-yl)propyl-1-phosphonic (Tocris Cookson, Bristol, UK). Membrane currents were recorded with an EPC8 or EPC9 amplifier (HEKA Elektronik, Lambrecht/Pfalz, Germany). The PULSE software (HEKA Elektronik) was used for stimulation and data acquisition. The signals were filtered at $3 \mathrm{kHz}$ and digitized at $20 \mathrm{kHz}$. Glass pipettes filled with normal saline were used to stimulate putative GABAergic fibers. We also performed cell-attached and whole-cell recordings from cholinergic interneurons identified with their large somata and firing properties (Kawaguchi, 
A

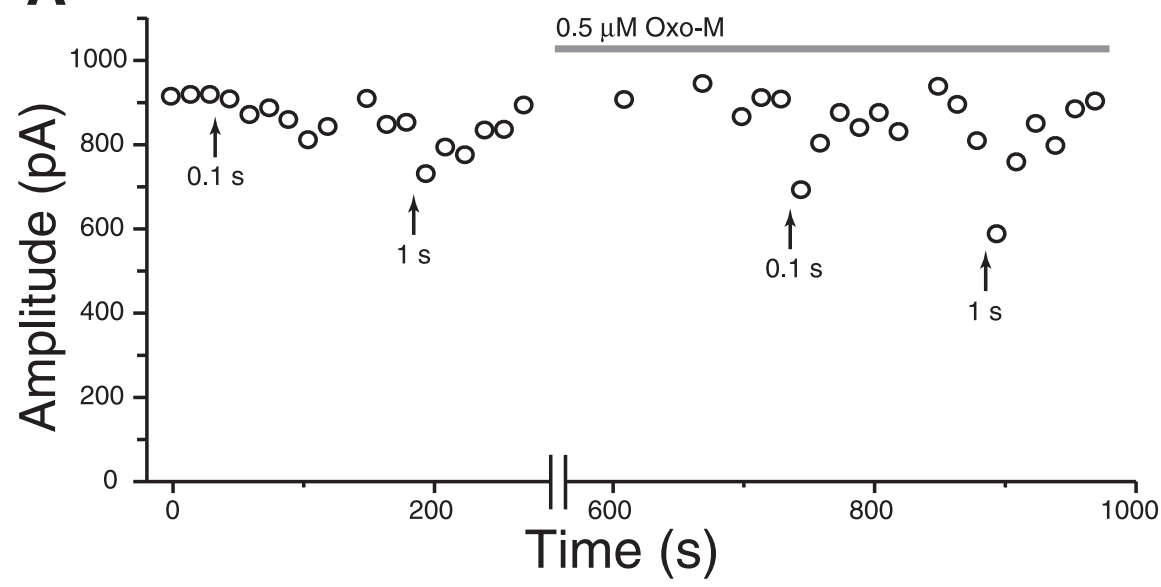

B Control

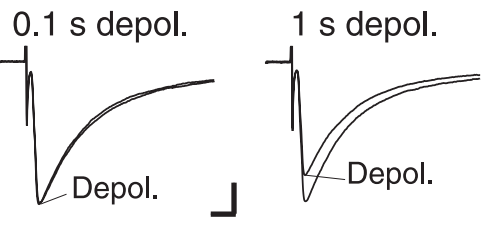

\section{$0.5 \mu \mathrm{M}$ Oxo-M}

$0.1 \mathrm{~s}$ depol.

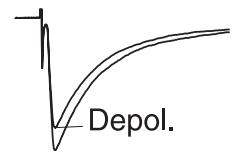

$1 \mathrm{~s}$ depol.

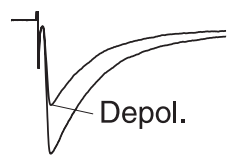

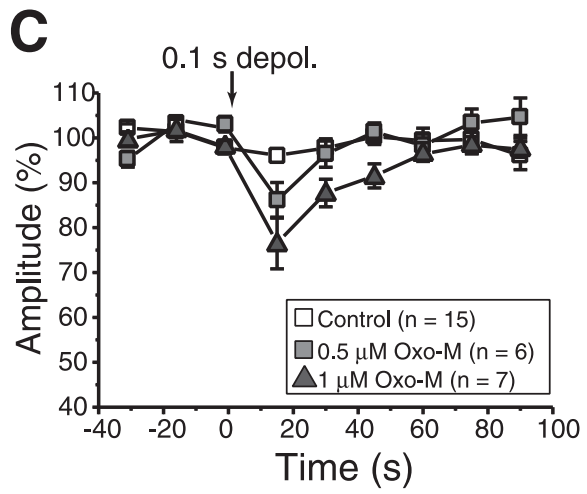
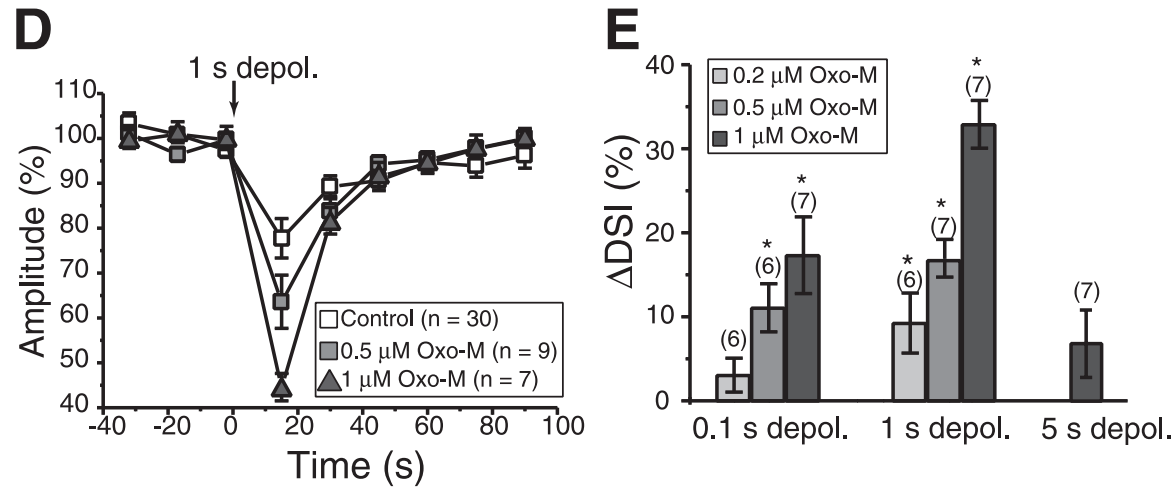

Figure 2. Enhancement of DSI by muscarinic receptor activation. $\boldsymbol{A}$, Representative data demonstrating enhancement of DSI by oxo-M. Each point represents the average of three consecutive traces. Depolarizing pulses with duration of 0.1 or $1 \mathrm{~s}$ were applied before and during oxo-M $(0.5 \mu \mathrm{M})$ application at the time points indicated with upward arrows. $B$, Examples of DSI recorded in the normal external solution (top) and in the presence of $0.5 \mu \mathrm{m}$ 0xo-M (bottom). IPSCs were recorded at the indicated time points in $\boldsymbol{A}$. Calibration: $200 \mathrm{pA}, 5 \mathrm{~ms}$. C, D, Summary data showing dose-dependent enhancement by oxo-M of DSl induced by $0.1 \mathrm{~s}(\boldsymbol{C})$ or $1 \mathrm{~s}(\boldsymbol{D})$ depolarization. $\boldsymbol{E}$, Summary bar graphs showing the enhancement of DSI induced by $0.1 \mathrm{~s}$ (left), $1 \mathrm{~s}$ (middle), or $5 \mathrm{~s}$ (right) depolarization by oxo-M at indicated concentrations (in micromolar). ${ }^{*} p<0.05$. depol., Depolarization.

1993) with $\mathrm{K}^{+}$-based internal solution. In paired recording experiments, we made voltage-clamp recordings from an MS neuron adjacent to $(<100 \mu \mathrm{m})$ the cholinergic interneuron.

For testing effects of chemicals, two successive test pulses with an interstimulus interval of $50 \mathrm{~ms}$ were applied every $20 \mathrm{~s}$. All drugs except for guanosine- $5^{\prime}-O$ - (2-thiodiphosphate) (GDP- $\beta$-S) were bath applied. Effects of drugs were estimated as the percentage of the mean amplitudes of five consecutive IPSCs during drug application relative to that before application. Oxotremorine-M (oxo-M), AM281 [1-(2,4-dichlorophenyl)-5-(4-iodophenyl)-4-methyl- $N$-4-morpholinyl-1 $H$-pyrazole-3carboxamide], WIN55,212-2 [(R)-(+)-[2,3-dihydro-5-methyl-3-(4morpholinylmethyl)pyrrolo[1,2,3-de]-1,4-benzoxazin-6-yl]-1-naphthalenylmethanone mesylate], and ZD7288 were purchased from Tocris Cookson, atropine was from Nacalai Tesque (Kyoto, Japan), and GDP$\beta$-S was from Sigma (St. Louis, MO). SR141716A [ $N$-piperidino-5-(4chlorophenyl)-1-(2,4-dichlorophenyl)-4-methyl-3-pyrazole carboxamide] was a generous gift from Sanofi Recherche (Libourne, France).

Induction and estimation of DSI. In experiments for recording evoked IPSCs, two successive test pulses (duration, $0.1 \mathrm{~ms}$; amplitude, 0-90 V) with an interstimulus interval of $50 \mathrm{~ms}$ were applied every $5 \mathrm{~s}$ for monitoring the paired-pulse ratio. To induce DSI, a depolarizing pulse $(0.1,1$, or $5 \mathrm{~s}$ duration from -80 to $0 \mathrm{mV}$ ) was applied to MS neurons. The magnitude of suppression was calculated as the percentage of reduction in the mean of three consecutive response amplitudes after depolarization relative to that of 10 consecutive response amplitudes just before depolarization. sIPSCs were analyzed using Mini analysis program (Synaptosoft, Decatur, GA). Threshold for detecting sIPSC was set at the level three times larger than the noise level. To calculate suppression of sIPSCs, the membrane charges for detected sIPSCs were accumulated for $10 \mathrm{~s}$ before and after depolarization. Magnitude of DSI for sIPSC was calculated as the percentage of reduction in the accumulated membrane charge after depolarization relative to that before depolarization. To quantify enhancement of DSI by some experimental manipulation, $\Delta$ DSI was calculated by subtracting the DSI magnitude in the control condition from that after the experimental manipulation.

Statistics. Averaged data from different experiments are presented as mean \pm SEM. Statistical significance was assessed by Mann-Whitney $U$ test (for comparison of two independent samples) or Wilcoxon's signed rank test (for paired comparison of the same sample).

Antibodies for immunohistochemistry and immunoblotting. We used polyclonal antibodies to mouse $\mathrm{CB}_{1} \mathrm{R}$ (raised in the rabbit and guinea pig) (Fukudome et al., 2004; Kawamura et al., 2006), mouse dopamine $\mathrm{D}_{1}$ (guinea pig and goat) and $\mathrm{D}_{2}$ (rabbit and guinea pig) receptors $(\mathrm{Na}-$ rushima et al., 2006b), mouse parvalbumin (PV) (rabbit and goat) (Nakamura et al., 2004; Miura et al., 2006), mouse vesicular acetylcholine transporter VAChT (rabbit and goat) (Nakamura et al., 2004; Miura et al., 2006), and somatostatin (sc-13099; Santa Cruz Biotechnology, Santa Cruz, CA). In addition, we produced specific antibodies to mouse muscarinic $M_{1}$ receptor (amino acid residues 247-345; GenBank accession number NM007698, rabbit), mouse high-affinity choline transporter CHT1 (amino acid residues 531-580; GenBank accession number BC022025, rabbit and goat), mouse neuronal nitric oxide synthase (nNOS) (amino acid residues 1415-1429; GenBank accession number NM008712, rabbit and guinea pig), and glutathione-S transferase (GST) fusion proteins were used as antigens and GST-free polypeptides were for affinity purification, as reported previously (Nakamura et al., 2004). The antigenic regions for $\mathrm{M}_{1}$ and nNOS were chosen by low-sequence homology to other subtypes, i.e., $\mathrm{M}_{3} / \mathrm{M}_{5}$ muscarinic receptors (see Fig. 7A) 


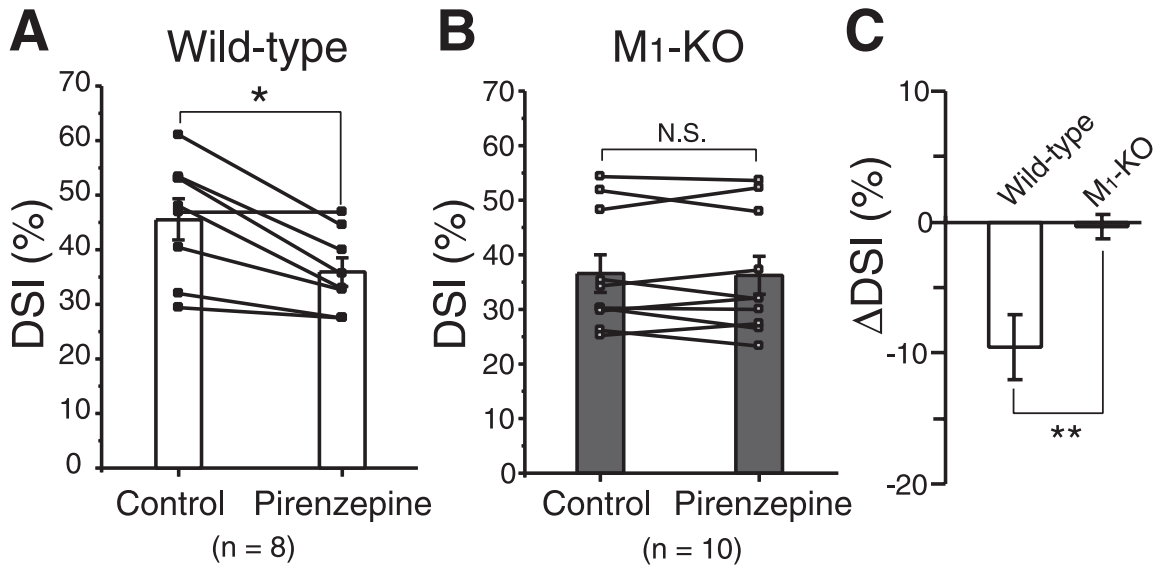

Figure 3. Ambient ACh tonically enhances DSI. $A, B$, Summary bar graphs and data from individual cells showing the magnitudes of DSI induced by $5 \mathrm{~s}$ depolarization with or without pirenzepine $(1 \mu \mathrm{m})$ for wild-type $(\boldsymbol{A})$ and $\mathrm{M}_{1}$ knock-out $(\boldsymbol{B})$ mice. Data from the same cells are connected. ${ }^{*} p<0.05$. C, Summary bar graph showing the pirenzepine-induced change in DSI magnitude $(\Delta D S I)$ for wild-type and $M_{1}$ knock-out mice. ${ }^{* *} p<0.01$.

and inducible NOS/endothelial NOS (data not shown), respectively. Specificities of $\mathrm{M}_{1}, \mathrm{CHT} 1$, and nNOS antibodies were checked by immunoblot detection of single protein bands at 64,65 , and $160 \mathrm{kDa}$, respectively (see Fig. 7B) (supplemental Fig. 2A,E, available at www.jneurosci. org as supplemental material).

Immunofluorescence. The parasagittal sections (50 $\mu \mathrm{m}$ in thickness) were incubated at room temperature in the free-floating method using PBS/0.1\% Triton X-100 for antibody diluent and washing buffer. After blocking with $10 \%$ normal donkey serum for $20 \mathrm{~min}$, sections were incubated overnight with a mixture of primary antibodies at the concentration of $1 \mu \mathrm{g} / \mathrm{ml}$ for each. Then, they were incubated for $2 \mathrm{~h}$ with a mixture of indocarbocyanine-, indodicarbocyanine-, or Alexa fluor 488labeled species-specific secondary antibodies (1:200; Jackson ImmunoResearch, West Grove, PA; Invitrogen, Carlsbad, CA). Single optical sections were taken with a confocal laser scanning microscope (FV1000; Olympus Optical).

The specificity was confirmed by distribution pattern of $M_{1}$ immunostaining identical to that of $M_{1}$ mRNA in the adult mouse brain and by the lack of immunostaining in the $\mathrm{M}_{1}$ knock-out $\left(\mathrm{M}_{1}-\mathrm{KO}\right)$ brain (see Fig. $7 C-E)$. The specificity of CHT1 and nNOS immunohistochemistry was confirmed by the lack of characteristic staining with use of antibodies preabsorbed with antigens (supplemental Fig. 2C, $G$, available at www. jneurosci.org as supplemental material) and also by selective coexpressions of CHT1 with VAChT in striatal cholinergic interneurons (Nakamura et al., 2004) and of nNOS in somatostatin-containing striatal neurons (supplemental Fig. $2 \mathrm{D}, \mathrm{H}$, available at www.jneurosci.org as supplemental material). The specificity was further ascertained by obtaining the same results with the use of primary antibodies raised for the same antigens in different species (data not shown).

Immunoelectron microscopy. The microslicer sections were permeabilized with $0.02 \%$ saponin for $30 \mathrm{~min}$, and $0.004 \%$ saponin was added to diluent of blocking serum to facilitate tissue penetration of primary and secondary antibodies. Sections were incubated overnight with $M_{1}$ antibody $(1 \mu \mathrm{g} / \mathrm{ml})$ and then with anti-rabbit IgG conjugated with colloidal gold for $2 \mathrm{~h}$ (1.4 nm in diameter, Nanogold; Nanoprobes, Stony Brook, NY). After silver enhancement (HQ silver; Nanoprobes), sections were treated with $0.5 \%$ osmium tetroxide, stained in block with $2 \%$ uranyl acetate, dehydrated, and embedded in Epon 812. Ultrathin sections were prepared from $<1.5 \mu \mathrm{m}$ from the section surface, mounted on nickel grids, and stained with $2 \%$ uranyl acetate for $10 \mathrm{~min}$. Electron micrographs were taken randomly by an H7100 electron microscope (Hitachi, Tokyo, Japan). The number of metal particles and the length of plasma membrane were measured on electron micrographs, using an IPLab software (Nippon Roper, Tokyo, Japan). Statistical significance was assessed by Student's $t$ test.

Immunoblot. Under pentobarbital anesthesia $(100 \mathrm{mg} / \mathrm{kg}$ of body weight, i.p.), brains were freshly removed from the skull, and the forebrain was quickly dissected and homogenized using a Potter homogenizer in $10 \mathrm{vol}$ of ice-cold buffer containing $320 \mathrm{~mm}$ sucrose, $1 \mathrm{~mm}$ EDTA, $20 \mathrm{~mm} \mathrm{KCl}, 10$ $\mathrm{mm}$ Tris- $\mathrm{HCl}, \mathrm{pH}$ 7.0, and an appropriate amount of protease inhibitor cocktail (Sigma). Homogenates were centrifuged for $10 \mathrm{~min}$ at $1000 \times g$, and the supernatant (i.e., the postnuclear or S1 fraction) was used for specificity test of antibody. Proteins were separated by $10 \%$ SDS-PAGE and then electroblotted onto nitrocellulose membranes (Schleicher and Schell, Dassel, Germany). After blocking with $5 \%$ skimmed milk for $2 \mathrm{~h}$, membranes were incubated with primary antibody $(1 \mu \mathrm{g} / \mathrm{ml})$ diluted with Tris-buffered saline, $\mathrm{pH} 7.5$, containing $0.1 \%$ Tween 20 and 5\% skimmed milk for $2 \mathrm{~h}$ and then with peroxidase-linked secondary antibody (1:15000; Amersham Biosciences, Tokyo, Japan) for $1 \mathrm{~h}$. Immunoreaction was visualized with the ECL chemiluminescence detection system (Amersham Biosciences).

In situ hybridization. Under deep pentobarbital anesthesia, the brains were freshly obtained from C57BL/6J mice at $2-3$ months of age. Fresh frozen sections ( $20 \mu \mathrm{m}$ thickness) were cut with a cryostat (CM1900; Leica, Nussloch, Germany) and mounted on glass slides precoated with 3-aminopropyltriethoxysilane. Oligonucleotide probes for $M_{1}$ mRNA (5'-gcctgtcactgtagccagagacaggaggcctgtggttgatccgat- $3^{\prime}$, antisense to nucleotide residues $112-156$ ) were synthesized and radiolabeled for in situ hybridization. Sections were treated at room temperature with the following incubation steps: fixation with $4 \%$ paraformaldehyde- $0.1 \mathrm{~m}$ sodium phosphate buffer, $\mathrm{pH} 7.2$, for $10 \mathrm{~min}, 2 \mathrm{mg} / \mathrm{ml}$ glycine-PBS, pH 7.2, for $10 \mathrm{~min}$, acetylation with $0.25 \%$ acetic anhydride in $0.1 \mathrm{M}$ triethanolamine- $\mathrm{HCl}, \mathrm{pH} 8.0$, for $10 \mathrm{~min}$, and prehybridization for $1 \mathrm{~h}$ in a buffer containing $50 \%$ formamide, $50 \mathrm{~mm}$ Tris- $\mathrm{HCl}, \mathrm{pH} 7.5$, $0.02 \%$ Ficoll, $0.02 \%$ polyvinylpyrrolidone, $0.02 \%$ bovine serum albumin, $0.6 \mathrm{~m} \mathrm{NaCl}, 0.25 \%$ SDS, $200 \mu \mathrm{g} / \mathrm{ml}$ tRNA, $1 \mathrm{~mm}$ EDTA, and $10 \%$ dextran sulfate. Hybridization was performed at $42^{\circ} \mathrm{C}$ for $12 \mathrm{~h}$ in the prehybridization buffer supplemented with $10,000 \mathrm{cpm} / \mu \mathrm{l}\left[{ }^{33} \mathrm{P}\right] \mathrm{dATP}-$ labeled oligonucleotides. Slides were washed twice at $55^{\circ} \mathrm{C}$ for $40 \mathrm{~min}$ in $0.1 \times$ SSC containing $0.1 \%$ sarcosyl. Sections were exposed for 3 weeks to BioMax x-ray films (Eastman Kodak, Rochester, NY).

\section{Results}

Postsynaptic $M_{1}$ receptor activation induces endocannabinoid-mediated suppression of inhibition to MS neurons

We began by examining mAChR subtype(s) involved in muscarinic suppression of inhibitory synaptic transmission onto MS neurons. We stimulated inhibitory synaptic inputs with a glass microelectrode placed near the MS neuron under recording $(<50 \mu \mathrm{m})$. Bath application of an mAChR agonist, oxo-M (1 $\mu \mathrm{M})$, reduced the amplitudes of IPSCs $(63.8 \pm 4.8 \%$ of control; $n=9$ ) (Fig. 1A,C). This suppression accompanied a significant change in the paired-pulse ratio $(0.70 \pm 0.03$ to $0.81 \pm 0.03 ; n=$ 9; $p=0.02$ ) (Fig. $1 A$ ), indicating that the suppression was of presynaptic origin. This effect of oxo-M on IPSCs was blocked by an $\mathrm{mAChR}$ antagonist, atropine (10 $\mu \mathrm{M}$, IPSC amplitude; $94.6 \pm$ $3.1 \%$ of control; $p=0.0007 ; n=9$; data not shown).

To determine whether presynaptic or postsynaptic mAChRs are responsible for this inhibition, we inactivated postsynaptic $\mathrm{mAChR}$ signaling cascade by loading GDP- $\beta$-S ( $2 \mathrm{~mm}$ ) into postsynaptic MS neurons. Infusion of GDP- $\beta$-S effectively reduced the oxo-M-induced suppression of IPSCs $(87.9 \pm 5.5 \%$ of control; $p=0.009$ compared with the oxo-M effect in normal pipette solution; $n=11$ ) (Fig. $1 B, C$ ), indicating that postsynap- 
tic mAChRs are important for the presynaptic suppression of IPSCs. Application of the $M_{1}$ receptor-preferring antagonist pirenzepine $(1 \mu \mathrm{M})$ effectively blocked the oxo-M-induced suppression of IPSCs $(96.8 \pm 3.9 \%$ of control; $p=0.0005 ; n=$ 9) (Fig. $1 B, C$ ). Because pirenzepine also blocks $\mathrm{M}_{4}$ receptors at higher concentrations, we examined $\mathrm{M}_{1}-\mathrm{KO}$ mice (OhnoShosaku et al., 2003). Basic properties of inhibitory synaptic transmission recorded in MS neurons were normal in $\mathrm{M}_{1}-\mathrm{KO}$ mice (IPSC amplitude, $829.8 \pm 36.7 \mathrm{pA}$ in wild-type, $n=65$ vs $909.3 \pm 63.5 \mathrm{pA}$ in $\mathrm{M}_{1}-\mathrm{KO}, n=39, p=0.1$; paired-pulse ratio, $0.70 \pm 0.01$ in wild-type vs $0.69 \pm 0.01$ in $\mathrm{M}_{1}-\mathrm{KO}, p=0.3$ by Student's $t$ test). oxo-M (1 $\mu \mathrm{M})$-induced suppression of IPSC in $\mathrm{M}_{1}$-KO mice was much smaller than that in wild-type mice $(89.7 \pm 4.1 \%$ of control; $p=0.0009 ; n=9$ ) (Fig. $1 B, C$ ). These results indicate that the postsynaptic $M_{1}$ receptor is responsible for cholinergic modulation of inhibitory transmission in MS neurons.

This oxo-M-induced suppression of IPSC was markedly reduced by AM281 (3 $\mu \mathrm{M})$, a cannabinoid receptor antagonist $(89.9 \pm 4.0 \%$ of control; $p=0.009 ; n=9)$ (Fig. $1 B$ ). This result clearly indicates that oxo-M-induced suppression of inhibitory synaptic transmission involves endocannabinoid signaling.

It should be noted that a small suppression of IPSCs remained under the blockade of postsynaptic G-protein cascade (by GDP- $\beta-S$ ) or $\mathrm{CB}_{1}$ receptors (by AM281) (Fig. $1 B, C$ ). The magnitude of this residual suppression was similar to that of the oxo-M-induced suppression of IPSCs in $\mathrm{M}_{1}-\mathrm{KO}$ mice (Fig. $1 B, C)$. We assume that the residual suppression was caused by direct activation of presynaptic $\mathrm{mAChR}$, presumably $\mathrm{M}_{4}$ receptors reported to be expressed in GABAergic interneurons (Hersch et al., 1994). Nevertheless, the present results clearly indicate that the major component of the muscarinic suppression of IPSCs is mediated by postsynaptic $M_{1}$ receptors and involves retrograde endocannabinoid signaling.

\section{DSI is constitutively upregulated by ambient ACh through the $M_{1}$ receptor}

It is now well established that endocannabinoids act as a retrograde messenger at excitatory and inhibitory synapses in various regions of the brain (Piomelli, 2003). It has also been reported that coincidence of $\mathrm{mAChR}$ activation and postsynaptic $\mathrm{Ca}^{2+}$ elevation supralinearly facilitates endocannabinoid production in the hippocampus (Kim et al., 2002; Ohno-Shosaku et al., 2003). We tested whether similar cooperativity was observed in MS neurons of the striatum. As shown in Figure 2A, 0.1 s depolarization of an MS neuron in standard extracellular solution caused no perceptible depression of IPSCs, whereas $1 \mathrm{~s}$ depolarization caused a small suppression. With a low concentration of oxo-M $(0.5 \mu \mathrm{M})$, which by itself did not affect basal synaptic transmission, $0.1 \mathrm{~s}$ depolarization now induced clear suppression

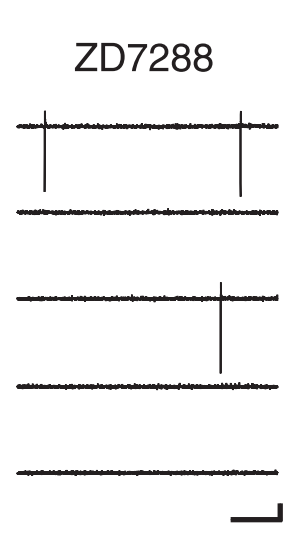

B
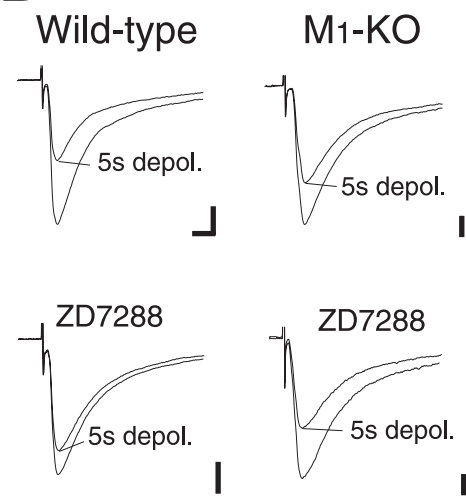

I
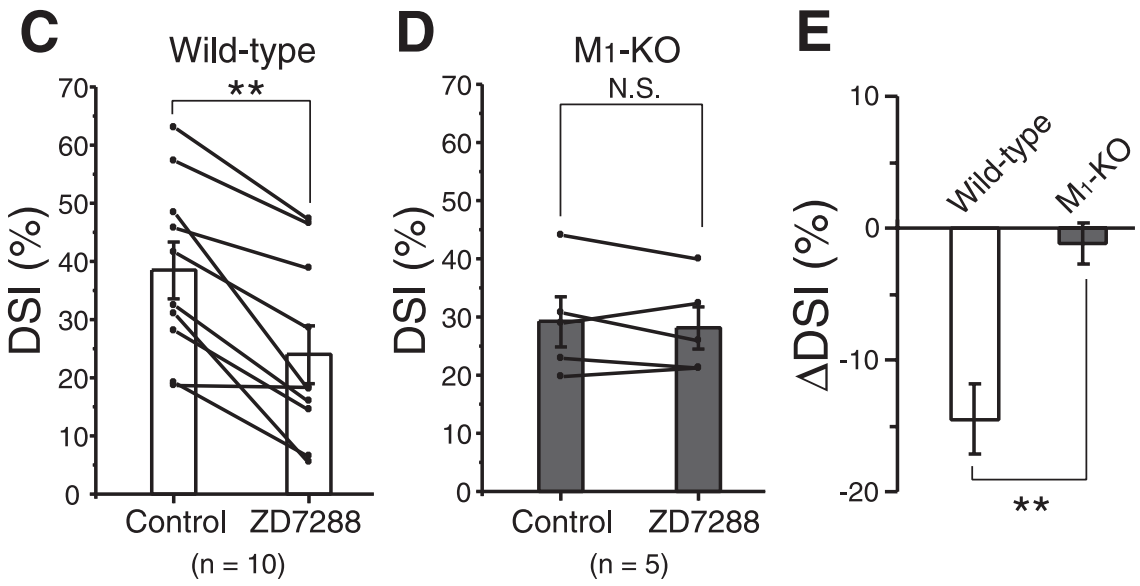

I

Figure 4. Ambient ACh concentration regulates the magnitude of DSI. A, Sample records showing the effect ofZD7288 (20 $\mu \mathrm{m})$ and $M_{1}$ knock-out $(\boldsymbol{D})$ mice. Data from the same cells are connected. ${ }^{* *} p<0.01$. $\boldsymbol{E}$, Summary bar graph showing the ZD7288induced change in DSI magnitude ( $\triangle D$ DSI) for wild-type and $\mathrm{M}_{1}$ knock-out mice. ${ }^{* *} p<0.01$.

of IPSCs, and $1 \mathrm{~s}$ depolarization induced even more pronounced suppression (Fig. $2 A, B$ ). For 0.1 s depolarization, the suppression was $4.9 \pm 1.7 \%$ in control and $14.0 \pm 3.5 \%$ in $0.5 \mu \mathrm{M}$ oxo-M $(n=6)$. For $1 \mathrm{~s}$ depolarization, the suppression was $20.7 \pm 4.2 \%$ in control and $35.6 \pm 5.9 \%$ in oxo-M at $0.5 \mu \mathrm{M}(n=7)$. We then investigated dose dependency of oxo-M on DSI. As summarized in Figure 2, $C$ and $D$, oxo-M enhanced suppression induced by $0.1 \mathrm{~s}$ (Fig. 2C) and $1 \mathrm{~s}$ (Fig. 2D) depolarization in a dosedependent manner. Threshold dose of significant enhancement of DSI was $0.5 \mu \mathrm{M}$ for $0.1 \mathrm{~s}$ depolarization and $0.2 \mu \mathrm{M}$ for $1 \mathrm{~s}$ depolarization (Fig. 2 E). For $5 \mathrm{~s}$ depolarization, $1 \mu \mathrm{M}$ oxo-M did not induce significant enhancement of DSI ( $\Delta$ DSI, $6.5 \pm 4.1 \%$; $n=7 ; p=0.17$ ) (Fig. $2 E$ ), suggesting that $5 \mathrm{~s}$ or longer depolarization causes maximum activation of endocannabinoidproducing machinery in MS neurons. These results indicate that $\mathrm{mAChR}$ activation and postsynaptic depolarization supralinearly facilitated endocannabinoid production in striatal MS neurons as in the hippocampus.

In the striatum, cholinergic interneurons exhibit tonic spontaneous firing in intact animals (Wilson et al., 1990), and similar activity was shown in striatal slices (Bennett and Wilson, 1999). We examined whether intrinsic cholinergic system can modulate endocannabinoid-induced signaling in MS neurons. First, we found that inhibition of postsynaptic G-proteins by applying 
GDP- $\beta$-S from the recording pipette significantly reduced the magnitude of DSI. DSI amplitude induced by $5 \mathrm{~s}$ depolarization was $44.2 \pm 2.7 \%(n=36)$ with normal intracellular solution but $35.5 \pm 2.2 \%$ with GDP- $\beta$-S-containing solution $(n=7 ; p=0.04$; data not shown). This result suggests that postsynaptic G-protein cascade contributes to tonic enhancement of DSI. Next, we measured the magnitudes of DSI before and after pirenzepine application in the same neurons. As summarized in Figure $3 A$, suppression induced by $5 \mathrm{~s}$ depolarization became significantly smaller after pirenzepine application in wild-type mice $(p=$ $0.02 ; n=8)$. Reduction in the magnitude of DSI $(\Delta \mathrm{DSI})$ was $-9.5 \pm 2.4 \%$ for $5 \mathrm{~s}$ depolarization $(n=8)$ (Fig. $3 A, C)$. We then examined DSI by $5 \mathrm{~s}$ depolarization in $\mathrm{M}_{1}-\mathrm{KO}$ mice. In contrast to wild-type mice, pirenzepine had no effect on the magnitude of DSI in $\mathrm{M}_{1}$-KO mice ( $\Delta$ DSI, $-0.3 \pm 1.0 \% ; p=0.6 ; n=10$ ) (Fig. $3 B, C$ ). Pirenzepine alone had no effect on IPSC amplitude (wildtype, $105.4 \pm 2.6 \%, n=7 ; \mathrm{M}_{1}-\mathrm{KO}, 99.7 \pm 3.7 \%, n=10$; data not illustrated), indicating no tonic suppression of inhibitory transmission. Moreover, we found that the magnitude of basal DSI in $\mathrm{M}_{1}$-KO mice $(34.8 \pm 2.4 \% ; n=40)$ was significantly $(p=0.02)$ smaller than that in wild-type mice $(44.1 \pm 2.3 \% ; n=41)$. These results suggest that the endocannabinoid release mechanism is constitutively upregulated through $\mathrm{M}_{1}$ receptor activation by ambient ACh, although the concentration of ambient ACh is not high enough to trigger endocannabinoid synthesis by itself.

\section{Firing of cholinergic interneuron influences endocannabinoid-mediated suppression}

Suppression of cholinergic interneuron activity is expected to lower ambient ACh concentration and affect endocannabinoid signaling in MS neurons. In the striatum, only cholinergic interneurons possess $I_{\mathrm{h}}$ current (Kawaguchi, 1993). Blockade of $I_{\mathrm{h}}$ current hyperpolarizes cholinergic interneurons and blocks their spontaneous tonic firings (Bennett et al., 2000). Therefore, we applied an $I_{\mathrm{h}}$ channel blocker, ZD7288 $(20 \mu \mathrm{M})$, to suppress firing of cholinergic interneurons. We monitored their activity with cell-attached recording mode and found that their firing rates were greatly reduced from $2.7 \pm 0.6$ to $0.3 \pm 0.1 \mathrm{~Hz}(p=0.03$; $n=6$ ) after $15 \mathrm{~min}$ of ZD7288 application (Fig. $4 A$ ). Then we performed whole-cell recordings from MS neurons and measured the magnitude of DSI before and during ZD7288 treatment. Suppression of IPSCs induced by $5 \mathrm{~s}$ depolarization was greatly attenuated after ZD7288 application $(n=10)$ (Fig. $4 B, D)$. In $\mathrm{M}_{1}$-KO mice, ZD7288 had no effect on the amplitude of suppression $(p=0.3$ ) (Fig. $4 C, D$ ). These results support that endogenous $\mathrm{ACh}$ in the striatum is derived from cholinergic interneurons and indicate that suppression of their spontaneous firings lowers ambient $\mathrm{ACh}$ level and blocks $\mathrm{M}_{1}$-mediated tonic enhancement of endocannabinoid release mechanism.

We then tried to elevate ambient ACh concentration in slices by applying choline esterase inhibitor, eserine, to the external solution. Eserine $(10 \mu \mathrm{M})$ significantly reduced IPSC amplitude $(n=6)$ (Fig. $5 A, B)$. This suppression was totally blocked by the $\mathrm{CB}_{1} \mathrm{R}$ antagonist SR141716A $(3 \mu \mathrm{M} ; n=6)$ or pirenzepine $(1 \mu \mathrm{M}$; $n=6$ ) (Fig. $5 A, B$ ). Moreover, eserine significantly enhanced suppression of IPSCs induced by $0.1 \mathrm{~s}(n=6)$ or $1 \mathrm{~s}(n=6)$ depolarization (Fig. 5C,D). This enhancement was completely blocked by pirenzepine $(n=5)$ (Fig. $5 C, D)$. These results indicate that constitutive upregulation of endocannabinoid signaling (Fig. 3) is enhanced by increasing ambient ACh. Together, these lines of evidence suggest that cholinergic activity can regulate striatal outputs by modulating endocannabinoid-mediated retrograde suppression of inhibition on MS neurons.

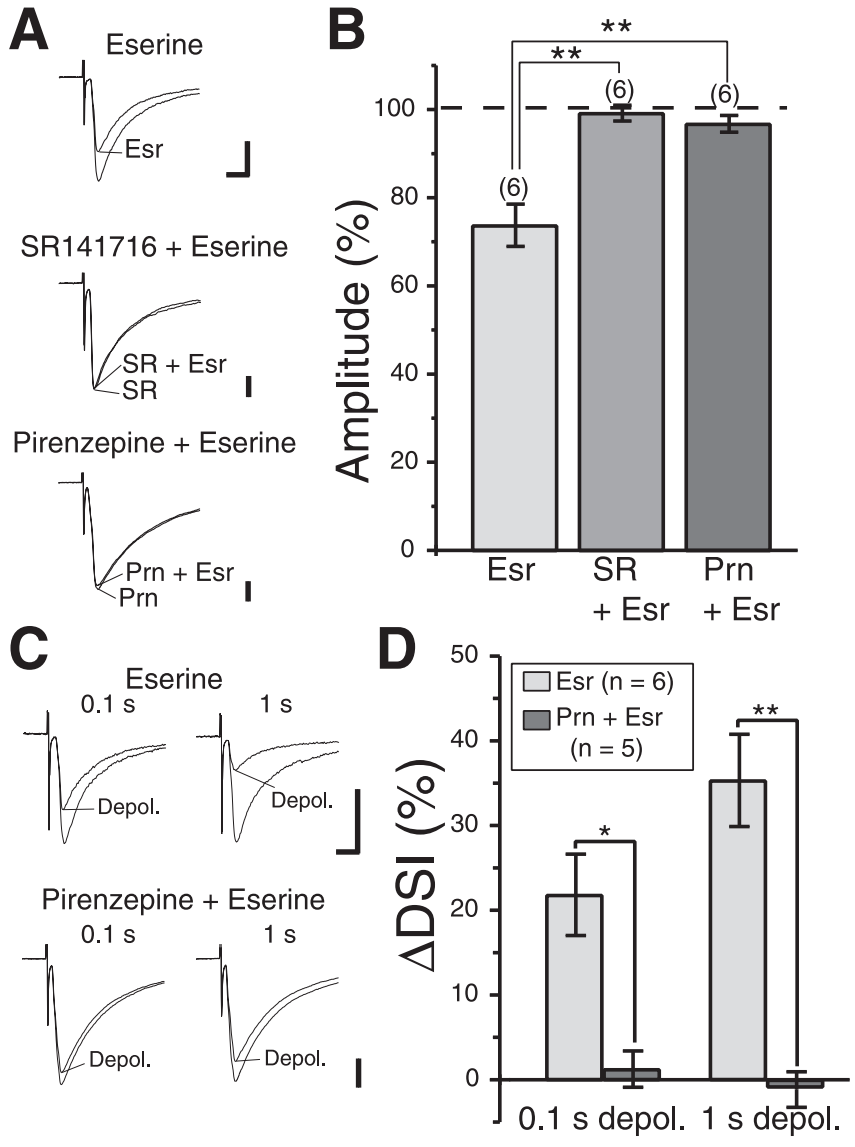

Figure 5. Elevation of ambient ACh concentration enhances DSI. $A$, Sample traces before and during bath application of a choline esterase inhibitor, eserine, in the standard extracellular solution (top), in the presence of SR141716A (middle), and in the presence of pirenzepine (bottom). Calibration: 200 pA, 5 ms. B, Summary bar graph showing the effect of eserine (10 $\mu \mathrm{M})$ application on IPSC amplitude for the following experimental conditions: Esr, eserine alone; SR + Esr, eserine in the presence of SR141716A (3 $\mu \mathrm{M}) ;$ Prn + Esr, eserine in the presence of pirenzepine $(1 \mu \mathrm{M}) .{ }^{* *} p<0.01$. C, Sample IPSC traces showing eserine-induced enhancement of suppression after $0.1 \mathrm{~s}$ (top left) and $1 \mathrm{~s}$ (top right) depolarizing pulses. The enhancement was reduced by pirenzepine application (bottom row). Calibration: 100 pA, 5 ms. $D$, Summary bar graphs showing eserine-induced enhancement of suppression after 0.1 and $1 \mathrm{~s}$ depolarizing pulses in the standard extracellular solution (left) and in the presence of pirenzepine (right). ${ }^{*} p<0.05 ;{ }^{* *} p<0.01$.

\section{Single cholinergic interneurons regulate endocannabinoid- mediated signaling in neighboring MS neurons}

To further investigate physiological relevance of endocannabinoidmediated modulation on inhibitory transmission, we checked whether DSI and its modulation by the cholinergic system are also observed in sIPSCs. We found that 1 or $5 \mathrm{~s}$ depolarization induced clear suppression of charge transfer mediated by sIPSCs and that this DSI was significantly enhanced by $0.5 \mu \mathrm{M}$ oxo-M (supplemental Fig. 1, available at www.jneurosci.org as supplemental material), which was essentially the same as DSI for evoked IPSCs. We then examined whether alteration of single cholinergic neuron activity could modulate DSI magnitude in neighboring MS neurons. For this purpose, we performed paired recording from a cholinergic interneuron (under current-clamp mode) and an MS neuron (under voltage-clamp mode). Cholinergic interneurons were characterized by prominent hyperpolarization followed by a sag in membrane potential in response to negative current injection (Fig. 6A). Conversely, these neurons exhibit tonic firings with positive current injection (Bennett et al., 2000). We found that DSI for sIPSC by $1 \mathrm{~s}$ depolarization (Fig. 
$6 B$, top, "MS depol." protocol; $C$, left; $D)$ was significantly enhanced $(n=8 ; p=$ 0.02 ) by preceding repetitive firing of the cholinergic interneuron (Fig. 6B, middle, "Ch spikes + MS depol." protocol; $C$, right; $D$ ). The repetitive firing of the cholinergic interneuron alone (Fig. 6B, bottom, "Ch spikes" protocol) had no effect on sIPSCs $(n=8)$ (Fig. $6 D)$. The enhancement was completely blocked by pirenzepine ( $p=0.5 ; n=5$ ) (Fig. $6 E$ ). Increase in the magnitude of suppression ( $\Delta$ suppression) was $21.0 \pm 5.9 \%$ in normal solution $(n=8)$ but $2.2 \pm 2.3 \%$ in the presence of pirenzepine $(n=5)$ (Fig. $6 F)$. These results indicate that $\mathrm{ACh}$ released from cholinergic interneurons modulates the magnitudes of DSI through activation of $M_{1}$ receptors in MS neurons. Because the activity of only one cholinergic interneuron in the slice could be controlled in this experiment, the results indicate that single cholinergic interneurons can regulate endocannabinoid-mediated signaling in neighboring MS neurons.

\section{$M_{1}$ is selectively expressed at somatodendritic domains of MS neurons in the striatum}

To obtain the morphological basis, we produced a specific antibody against mouse muscarinic $M_{1}$ receptor (Fig. $7 A, B)$ and examined its expression in the striatum (Fig. 8). We also raised antibodies against mouse high-affinity $\mathrm{CHT} 1$ and mouse nNOS to differentially label striatal interneurons (supplemental Fig. 2, available at www.jneurosci.org as supplemental material). We found that $M_{1}$ was highly expressed in the striatum, accumbens, olfactory tubercle, anterior olfactory nucleus, and hippocampus (Fig. $7 C-F)$. In the striatum, $\mathrm{M}_{1}$ was densely distributed in perikarya and dendrites of $\mathrm{D}_{1}\left(\mathrm{D}_{1} \mathrm{R}\right)$ or $\mathrm{D}_{2}\left(\mathrm{D}_{2} \mathrm{R}\right)$ receptor-positive $\mathrm{MS}$ neurons (Fig. $8 \mathrm{~A}$ ), whereas it was hardly detectable in perikarya and processes of parvalbumin-positive, nNOS-positive, or CHT1-positive interneurons (Fig. 8B-D).

Subcellular localization of $\mathrm{M}_{1}$ in $\mathrm{MS}$ neurons was assessed by the preembedding silver-enhanced immunogold method (Fig. $8 E-G)$. Metal particles representing $\mathrm{M}_{1}$ were detected in association with the cytoplasmic side of the cell membrane and membranous organelles, such as the smooth endoplasmic reticulum. They were distributed in spines, shafts of spiny dendrites, and thin perikaryal rims, all being suggestive of MS neurons. In particular, cell membrane-attached metal particles were detected on the extrasynaptic surface but not on the synaptic surface. When counting cell membrane-attached metal particles, the number per $1 \mu \mathrm{m}$ of the cell membrane was twice as high as on the somatic (0.70) and dendritic (0.81) surface than on the spine surface (0.37) (Fig. $8 H$ ). These densities were much higher than those on nerve terminals $(0.03)$ or myelin sheath $(0.00)$. On dendritic shafts, no particular accumulation of $\mathrm{M}_{1}$ around symmetrical synapses was discerned, because labeling density within $500 \mathrm{~nm}$ from the edge of symmetrical synapses $(0.83)$ was similar to that on the total dendritic surface (0.81). In the striatum, $\mathrm{M}_{1}$ is thus
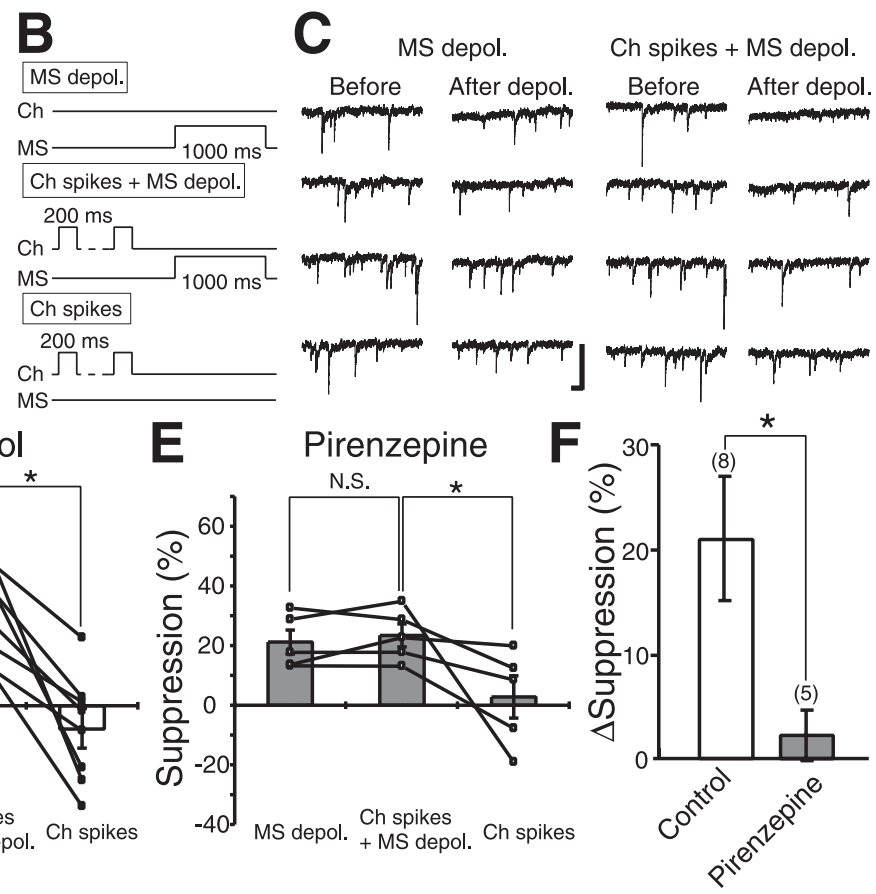

Figure 6. Paired recording from cholinergic interneurons and MS neurons. $\boldsymbol{A}$, Representative voltage traces from a cholinergic end of the cholinergic interneuron depolarization. Ch spikes, Repetitive depolarization of the cholinergic interneuronalone, Sample traces of spontaneous IPSC s before and after MS depol. (left) and Ch spikes + MS depol. protocols (right). Calibration: 100 Summary data showing the enhancement of DSI for spontaneous IPSCs by the firings of a cholinergic interneuron in standard extracellular solution and with pirenzepine. $\Delta$ Suppression was calculated by subtracting the magnitude of DSI for MS depol. protocol from that for Ch spikes + MS depol. protocol in the same MS neuron. ${ }^{*} p<0.05$.

preferentially expressed in the somatodendritic compartments of MS neurons and particularly enriched on the surface of perikarya and dendritic shafts.

\section{Discussion}

We presented evidence that indicates ambient ACh derived from tonically active cholinergic interneuron cannot trigger endocannabinoid release by itself but is sufficient to enhance depolarization-induced endocannabinoid signaling. Magnitude of DSI was decreased by suppression of cholinergic interneuron firing, whereas it was increased by inhibiting cholinesterase. This bidirectional modulation indicates that endocannabinoid release from MS neurons is strongly dependent on ambient ACh concentration. Furthermore, we demonstrated that activity of a single cholinergic neuron regulates endocannabinoid-mediated signaling in neighboring MS neurons. Because MS neurons send major outputs from the striatum, the present results collectively suggest a novel mechanism by which the cholinergic system can regulate striatal output and contribute to motor control.

\section{Cholinergic modulation of inhibitory synaptic transmission}

Inhibitory synapses in the striatum arise from local GABAergic interneurons and the recurrent collaterals of the MS neurons. The PV-positive and the somatostatin-positive interneurons form GABAergic inhibitory synapses onto MS neurons (Koos and Tepper, 1999; Kubota and Kawaguchi, 2000). Because these 

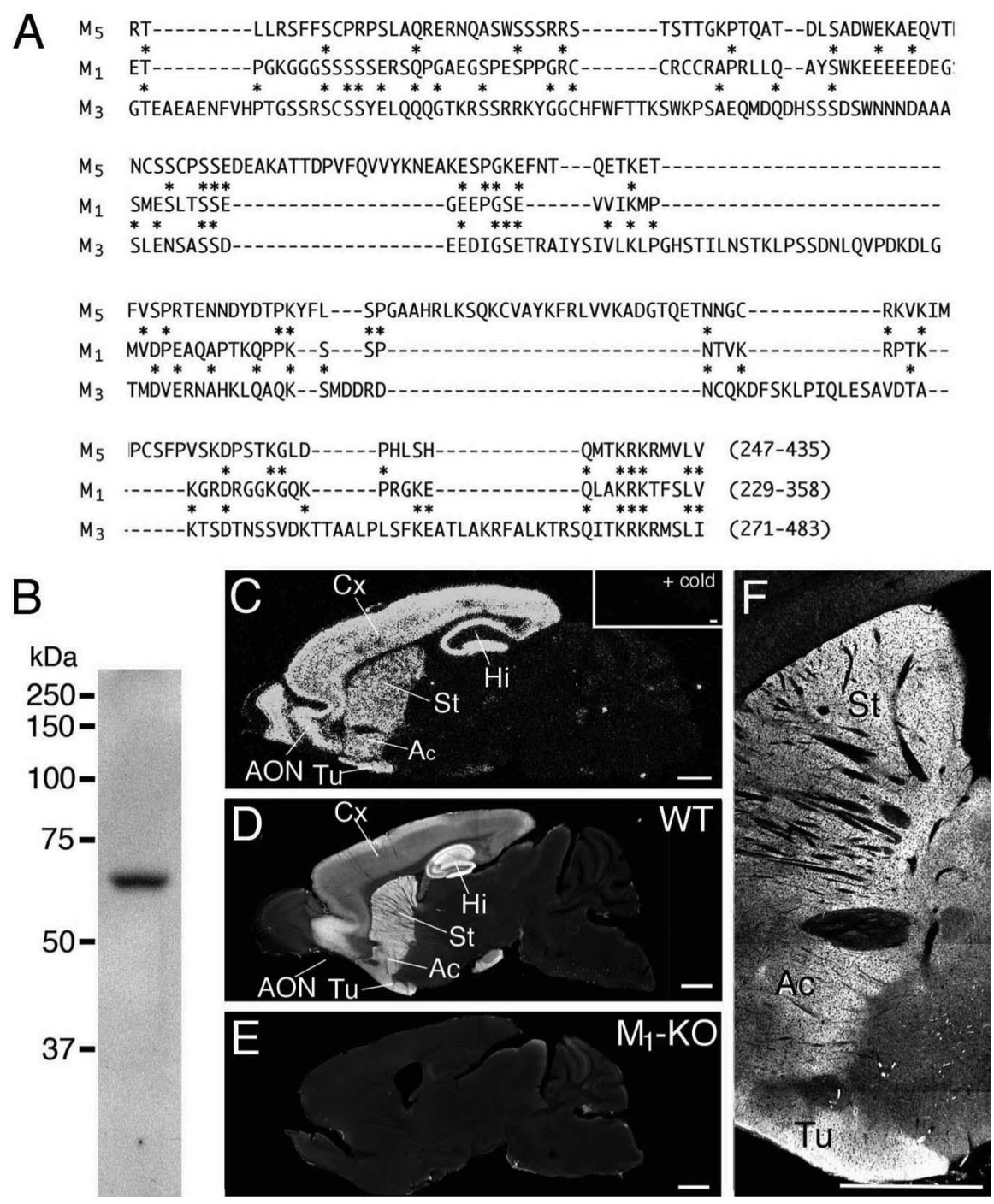

Figure 7. Production and characterization of antibodies against mouse $M_{1}$ receptor. $\boldsymbol{A}$, Low sequence homology of $M_{1}$ antigen polypeptide to corresponding regions of mouse $M_{3}$ and $M_{5}$ receptors. Asterisks indicate identical amino acid residues between $M_{1}$ and $M_{3}$ or $M_{1}$ and $M_{5}$. $B$, Immunoblot with protein samples from telencephalon. Rabbit $M_{1}$ antibody recognized single protein bands at $64 \mathrm{kDa}$. C, In situ hybridization showing preferential telencephalic expression of $M_{1}$ mRNA in the adult mouse brain. An inset shows the specificity of hybridization by the virtual disappearance of signals when hybridization was performed in the presence of unlabeled oligonucleotides in excess. $\boldsymbol{D}$, Immunofluorescence showing preferential telencephalic distribution of $M_{1}$ protein in the adult mouse brain. $\boldsymbol{E}$, The lack of $M_{1}$ immunostaining in the $M_{1}$ knock-out brain, indicating the specificity of $M_{1}$ immunohistochemistry. $\boldsymbol{F}$, An enlarged view of $\boldsymbol{D}$ around the striatum. Scale bars, $1 \mathrm{~mm}$. Ac, Accumbens; A0N, anterior olfactory nucleus; Cx, cortex; Hi, hippocampus; St, striatum; Tu, olfactory tubercle; WT, wild type.

two types of interneurons receive excitatory inputs from the cortex, they constitute feedforward inhibitory circuits in the striatum (Plenz, 2003; Tepper et al., 2004). In contrast, connections between MS neurons through their recurrent collaterals are observed much less frequently (Tepper et al., 2004), but they constitute feedback inhibitory circuits that are known to be modulated in an activity-dependent manner (Czubayko and Plenz, 2002). It has been reported recently that inhibitory inputs from PV-positive interneurons, which served strong feedforward inhibition to MS neurons, were suppressed by endocannabinoids after depolarization of MS neurons (Freiman et al., 2006; Narushima et al., 2006b). Together with this observation, our data suggest that the cholinergic system can modulate at least feedforward inhibition of MS neurons through endocannabinoidmediated pathways. It remains to be determined, however, whether inhibitory transmission originated from other sub- type(s) of interneurons or MS neurons also regulated by endocannabinoids and/or the cholinergic system.

It has been suggested that pirenzepinesensitive presumably $M_{1}$ receptors are involved in presynaptic inhibition of GABAergic inputs to MS neurons (Koos and Tepper, 2002). However, we demonstrated that $M_{1}$ receptor-mediated suppression of IPSCs required activation of postsynaptic G-protein cascade and presynaptic cannabinoid receptors. These results indicate that cholinergic inputs activate postsynaptic $M_{1}$ receptors and produce endocannabinoids through postsynaptic G-protein cascade and then released endocannabinoids suppress GABA release through presynaptic $C_{1}$ receptors.

Excitatory synaptic transmission to MS neurons is also presynaptically suppressed by cholinergic agonist (Calabresi et al., 2000) by direct activation of presynaptic mAChRs (Narushima et al., 2006a). Ambient ACh seemed to tonically inhibit excitatory inputs because atropine application itself increased amplitude of evoked EPSPs (Dodt and Misgeld, 1986). Thus, cortical excitatory inputs that overcome cholinergic tonic inhibition may activate MS neurons, and then the firing of MS neurons may trigger depolarizationinduced, $\mathrm{M}_{1}$-mediated endocannabinoid release and suppress local inhibitory transmission. It is possible that the cholinergic system highlights activated corticostriatal inputs but suppresses background excitation and thus improves the signal-to-noise ratio of corticostriatal information flow.

Although cholinergic suppression of excitatory transmission to MS neurons is independent of endocannabinoid signaling (Narushima et al., 2006a), corticostriatal excitatory synaptic terminals are sensitive to cannabinoids (Gerdeman et al., 2002). In MS neurons, excitatory synaptic terminals are located exclusively on dendritic spines, whereas inhibitory synaptic terminals are on dendritic shafts and somata (Kubota and Kawaguchi, 2000; Wilson, 2004). Although subcellular distributions of enzymes for endocannabinoid synthesis are not precisely known in MS neurons, the preferential somatodendritic localization of $M_{1}$ receptors as shown in the present study may explain the differential actions of endocannabinoids on excitatory and inhibitory synapses.

It has been reported recently that $\mathrm{M}_{1}$ activation tonically inhibits endocannabinoid release at glutamatergic synapses through suppression of $\mathrm{Ca}_{\mathrm{V}} 1.3$ channel-mediated $\mathrm{Ca}^{2+}$ currents (Wang et al., 2006). Thus, $M_{1}$ activation exerts opposite effects on endocannabinoid production at excitatory and inhibitory synapses. This might be attributable to the difference in subcellular localization of $\mathrm{M}_{1}$ and related signaling molecules between excitatory synapses on dendritic spines and inhibitory synapses on dendritic shafts and somata. The $\mathrm{M}_{1}$-mediated $\mathrm{Ca}_{\mathrm{V}} 1.3$ modula- 
tion was reported to require functional interaction among $\mathrm{Ca}_{\mathrm{V}} 1.3$, Shank, and Homer that form a protein complex with postsynaptic density-95 in dendritic spines (Olson et al., 2005). Because these signaling molecules are localized in dendritic spines of MS neurons (Olson et al., 2005; Day et al., 2006), $\mathrm{M}_{1}$ activation in the dendritic shaft and soma may not cause tonic suppression of endocannabinoid production at inhibitory synapses but rather enhance endocannabinoid synthesis through PLC $\beta$ as reported in the hippocampus (Kim et al., 2002; OhnoShosaku et al., 2003; Hashimotodani et al., 2005) and the cerebellum (Maejima et al., 2005).

Two endocannabinoid systems in the striatum

The striatum contains a moderate level of $\mathrm{CB}_{1} \mathrm{R}$ as investigated with ${ }^{3} \mathrm{H}$-labeled $\mathrm{CB}_{1} \mathrm{R}$ agonist binding (Herkenham et al., 1991). In rodents, cannabinoid administration produces impairments of basal ganglia-related behaviors, including decrease in spontaneous activity, induction of catalepsy, and increase in circling behavior (Romero et al., 2002). $\mathrm{CB}_{1} \mathrm{R}$ knockout mice have altered gene expression of various neuropeptides and transmitterrelated enzymes in the striatum (Steiner et al., 1999) and exhibit motor deficits related to the basal ganglia (Zimmer et al., 1999). Endocannabinoid signaling has been reported to be necessary for induction of corticostriatal long-term depression (LTD) (Gerdeman et al., 2002). These lines of evidence suggest that endocannabinoid signaling through $\mathrm{CB}_{1} \mathrm{R}$ in the striatum contributes to motor control.

Recent electrophysiological results using a DAG lipase inhibitor suggest that a candidate endocannabinoid, 2-arachidonoylglycerol (2-AG), can be released after postsynaptic depolarization and/or $\mathrm{G}_{\mathrm{q} / 11^{-}}$ coupled receptor activation and act as a retrograde messenger (Melis et al., 2004; Maejima et al., 2005). In the hippocampus, activation of $\mathrm{G}_{\mathrm{q} / 11}$-coupled $\mathrm{mAChRs}$ or group I mGluRs drives PLC $\beta 1$, produces DAG, and induces endocannabinoidmediated retrograde suppression of inhibition (Hashimotodani et al., 2005). Because DAG is the precursor for 2-AG, these data suggest that $2-A G$ is released by $G_{q / 11}$-coupled receptor activation. Together with the observation that $\mathrm{M}_{1}$ receptor activation can drive PLCs in MS neurons (Lin et al., 2004), our results suggest the possibility that $2-\mathrm{AG}$ is synthesized by $\mathrm{M}_{1}$ receptor activation in MS neurons.

Another candidate endocannabinoid, anandamide, is considered to be synthesized from phosphatidylethanolamine by $\mathrm{N}$-acyltransferase and phospholipase D (Piomelli, 2003). It is re-
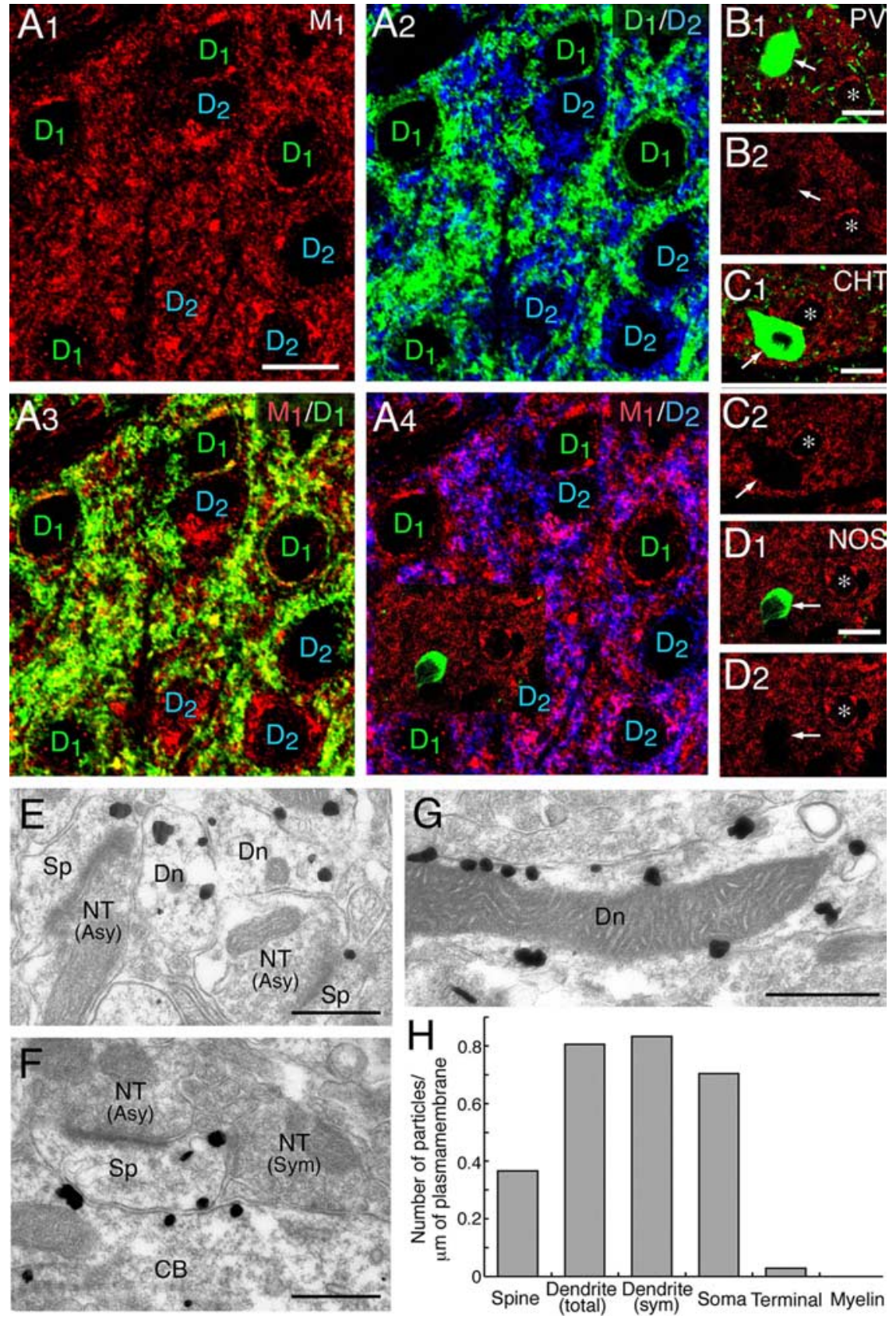

Figure 8. Muscarinic $M_{1}$ receptor is preferentially expressed in the somatodendritic compartments of $D_{1}$ - and $D_{2}$-positive $M S$ neurons. $A$, Triple labeling for $M_{1}$ (red), $D_{1}$ (green), and $D_{2}$ (blue) receptors. Note colabeling of $M_{1}$ with $D_{1}$ or $D_{2}$ receptors in thin perikaryal rims and neuropils. Scale bar, $10 \mu \mathrm{m}$. $\boldsymbol{B}-\boldsymbol{D}$, Arrows indicate interneurons expressing $\mathrm{PV}(\boldsymbol{B})$, high-affinity $\mathrm{CHT}(\boldsymbol{C})$, or neuronal NOS (D). Note vacant $M_{1}$ staining in these interneurons in contrast to abundant $M_{1}$ expression in perikarya of putative MS neurons (asterisks). Scale bars, $10 \mu \mathrm{m}$. $\boldsymbol{E}-\boldsymbol{G}$, Silver-enhanced immunogold microscopy for $M_{1}$ receptor. Note preferential $M_{1}$ labeling in spines (Sp), dendritic shafts (Dn), and cell bodies (CB) of putative MS neurons, in contrast to negative labeling in nerve terminals (NT) forming asymmetrical (Asy) and symmetrical (Sym) synapses. Scale bars, $1 \mu \mathrm{m}$. $\boldsymbol{H}$, The mean number of metal particles per $1 \mu \mathrm{m}$ of the cell membrane on spines (measured length, $177.5 \mu \mathrm{m}$ ), total dendrites $(173.9 \mu \mathrm{m})$, dendrites within $500 \mathrm{~nm}$ from the edge of symmetrical synapses $(12.0 \mu \mathrm{m})$, soma $(29.8 \mu \mathrm{m})$, nerve terminals $(71.5 \mu \mathrm{m})$, and myelin sheath $(33.4 \mu \mathrm{m})$.

ported that $\mathrm{D}_{2}$ but not $\mathrm{D}_{1}$ receptor activation increases striatal anandamide content in vivo (Giuffrida et al., 1999), suggesting that the striatal anandamide level is controlled by dopaminergic inputs specifically through $\mathrm{D}_{2}$ receptors. Moreover, anandamide appears to be important for LTD at the corticostriatal inputs (Gerdeman et al., 2002). However, mechanisms of anandamide production after $\mathrm{D}_{2}$ receptor activation or during LTD induction remain to be elucidated. 


\section{Functional implications of muscarinic modulation of striatal endocannabinoid system}

Striatal cholinergic system is crucial for proper functions of the basal ganglia. Mice ablated with unilateral cholinergic interneurons exhibit abnormal turning behavior to the contralateral side relative to the lesioned side (Kaneko et al., 2000). Moreover, several studies demonstrate that cholinergic interneuron activity can be changed dynamically in the striatum. For example, during sensorimotor learning in the primates, tonically active neurons (TANs), which correspond to cholinergic interneurons in rodents, change their activity in response to reward-related or aversive stimuli (Apicella, 2002). The firing rate of TANs, normally at $\sim 2-10 \mathrm{~Hz}$, exhibits a transient depression followed by a rebound excitation, which may influence ambient ACh concentration in the striatum (Aosaki et al., 1994). Other studies showed that striatal ACh content can be modulated depending on excitatory/ inhibitory balance (Bennett and Wilson, 1998) or by dopaminergic inputs (Reynolds et al., 2004).

In the present study, we disclosed for the first time a crosslink between muscarinic and endocannabinoid systems in the striatum. Importantly, tonic firing of cholinergic interneurons persistently activates $M_{1}$ receptors on MS neurons. This tonic $M_{1}$ activation by itself does not produce endocannabinoid, but it provides a state in which a relatively small amount of depolarization-induced $\mathrm{Ca}^{2+}$ influx can readily release endocannabinoids. In addition, our paired-recording study has revealed that the firing of single cholinergic interneuron is sufficient to activate $M_{1}$ receptor and to enhance endocannabinoid signaling in neighboring MS neurons. Cholinergic interneurons spontaneously fire at $\sim 3 \mathrm{~Hz}$, but they can fire at higher frequencies in vivo (Wilson et al., 1990; Aosaki et al., 1994). Therefore, the $\mathrm{M}_{1}$ mediated enhancement of the striatal endocannabinoid system appears to be physiologically relevant.

We recently reported that $C_{1} R$ is expressed at GABAergic terminals that synapse on both $\mathrm{D}_{1} \mathrm{R}$-positive and $\mathrm{D}_{2} \mathrm{R}$-positive MS neurons that constitute the direct and the indirect pathways, respectively (Narushima et al., 2006b). We demonstrate that $\mathrm{M}_{1}$ receptors are expressed in both $D_{1} R$-positive and $D_{2} R$-positive MS neurons. These results suggest that the cholinergic enhancement of endocannabinoid production can affect both the direct and indirect pathways. The released endocannabinoids retrogradely suppress inhibitory transmission and transiently enhance striatal outputs. This is in contrast to the dopaminergic modulation of anandamide production, which involves $D_{2}$ receptors (Giuffrida et al., 1999) and therefore presumably occurs only in MS neurons for the indirect pathway. Thus, the cholinergic and dopaminergic systems, which are well known to be crucial for proper functions of the basal ganglia, appear to exert their actions through endocannabinoid systems. We disclosed a novel mechanism by which the muscarinic system regulates striatal output through modulating endocannabinoid signaling.

\section{References}

Aosaki T, Tsubokawa H, Ishida A, Watanabe K, Graybiel AM, Kimura M (1994) Responses of tonically active neurons in the primate's striatum undergo systematic changes during behavioral sensorimotor conditioning. J Neurosci 14:3969-3984.

Apicella P (2002) Tonically active neurons in the primate striatum and their role in the processing of information about motivationally relevant events. Eur J Neurosci 16:2017-2026.

Bennett BD, Wilson CJ (1998) Synaptic regulation of action potential timing in neostriatal cholinergic interneurons. J Neurosci 18:8539-8549.

Bennett BD, Wilson CJ (1999) Spontaneous activity of neostriatal cholinergic interneurons in vitro. J Neurosci 19:5586-5596.
Bennett BD, Callaway JC, Wilson CJ (2000) Intrinsic membrane properties underlying spontaneous tonic firing in neostriatal cholinergic interneurons. J Neurosci 20:8493-8503.

Calabresi P, Centonze D, Gubellini P, Pisani A, Bernardi G (1998) Endogenous $\mathrm{ACh}$ enhances striatal NMDA-responses via $\mathrm{M}_{1}$-like muscarinic receptors and PKC activation. Eur J Neurosci 10:2887-2895.

Calabresi P, Centonze D, Gubellini P, Pisani A, Bernardi G (2000) Acetylcholine-mediated modulation of striatal function. Trends Neurosci 23:120-126.

Czubayko U, Plenz D (2002) Fast synaptic transmission between striatal spiny projection neurons. Proc Natl Acad Sci USA 99:15764-15769.

Day M, Wang Z, Ding J, An X, Ingham CA, Shering AF, Wokosin D, Ilijic E, Sun Z, Sampson AR, Mugnaini E, Deutch AY, Sesack SR, Arbuthnott GW, Surmeier DJ (2006) Selective elimination of glutamatergic synapses on striatopallidal neurons in Parkinson disease models. Nat Neurosci 9:251-259.

Dodt HU, Misgeld U (1986) Muscarinic slow excitation and muscarinic inhibition of synaptic transmission in the rat neostriatum. J Physiol (Lond) 380:593-608.

Freiman I, Anton A, Monyer H, Urbanski MJ, Szabo B (2006) Analysis of the effects of cannabinoids on identified synaptic connections in the caudate-putamen by paired recordings in transgenic mice. J Physiol (Lond) 575:789-806.

Fukudome Y, Ohno-Shosaku T, Matsui M, Omori Y, Fukaya M, Tsubokawa H, Taketo MM, Watanabe M, Manabe T, Kano M (2004) Two distinct classes of muscarinic action on hippocampal inhibitory synapses: M2mediated direct suppression and M1/M3-mediated indirect suppression through endocannabinoid signalling. Eur J Neurosci 19:2682-2692.

Gerdeman GL, Ronesi J, Lovinger DM (2002) Postsynaptic endocannabinoid release is critical to long-term depression in the striatum. Nat Neurosci 5:446-451.

Giuffrida A, Parsons LH, Kerr TM, Rodriguez de Fonseca F, Navarro M, Piomelli D (1999) Dopamine activation of endogenous cannabinoid signaling in dorsal striatum. Nat Neurosci 2:358-363.

Hashimotodani Y, Ohno-Shosaku T, Tsubokawa H, Ogata H, Emoto K, Maejima T, Araishi K, Shin HS, Kano M (2005) Phospholipase C $\beta$ serves as a coincidence detector through its $\mathrm{Ca}^{2+}$ dependency for triggering retrograde endocannabinoid signal. Neuron 45:257-268.

Herkenham M, Lynn AB, de Costa BR, Richfield EK (1991) Neuronal localization of cannabinoid receptors in the basal ganglia of the rat. Brain Res 547:267-274.

Hersch SM, Gutekunst CA, Rees HD, Heilman CJ, Levey AI (1994) Distribution of $\mathrm{m} 1-\mathrm{m} 4$ muscarinic receptor proteins in the rat striatum: light and electron microscopic immunocytochemistry using subtype-specific antibodies. J Neurosci 14:3351-3363.

Hohmann AG, Herkenham M (2000) Localization of cannabinoid $\mathrm{CB}_{1}$ receptor mRNA in neuronal subpopulations of rat striatum: a double-label in situ hybridization study. Synapse 37:71-80.

Howe AR, Surmeier DJ (1995) Muscarinic receptors modulate N-, P-, and L-type $\mathrm{Ca}^{2+}$ currents in rat striatal neurons through parallel pathways. J Neurosci 15:458-469.

Kaneko S, Hikida T, Watanabe D, Ichinose H, Nagatsu T, Kreitman RJ, Pastan I, Nakanishi S (2000) Synaptic integration mediated by striatal cholinergic interneurons in basal ganglia function. Science 289:633-637.

Kawaguchi Y (1993) Physiological, morphological, and histochemical characterization of three classes of interneurons in rat neostriatum. J Neurosci 13:4908-4923.

Kawamura Y, Fukaya M, Maejima T, Yoshida T, Miura E, Watanabe M, Ohno-Shosaku T, Kano M (2006) The $\mathrm{CB}_{1}$ cannabinoid receptor is the major cannabinoid receptor at excitatory presynaptic sites in the hippocampus and cerebellum. J Neurosci 26:2991-3001.

Kim J, Isokawa M, Ledent C, Alger BE (2002) Activation of muscarinic acetylcholine receptors enhances the release of endogenous cannabinoids in the hippocampus. J Neurosci 22:10182-10191.

Kita T, Kita H, Kitai ST (1984) Passive electrical membrane properties of rat neostriatal neurons in an in vitro slice preparation. Brain Res 300:129-139.

Koos T, Tepper JM (1999) Inhibitory control of neostriatal projection neurons by GABAergic interneurons. Nat Neurosci 2:467-472.

Koos T, Tepper JM (2002) Dual cholinergic control of fast-spiking interneurons in the neostriatum. J Neurosci 22:529-535. 
Kubota Y, Kawaguchi Y (2000) Dependence of GABAergic synaptic areas on the interneuron type and target size. J Neurosci 20:375-386.

Lin JY, Chung KK, de Castro D, Funk GD, Lipski J (2004) Effects of muscarinic acetylcholine receptor activation on membrane currents and intracellular messengers in medium spiny neurones of the rat striatum. Eur J Neurosci 20:1219-1230.

Maejima T, Oka S, Hashimotodani Y, Ohno-Shosaku T, Aiba A, Wu D, Waku K, Sugiura T, Kano M (2005) Synaptically driven endocannabinoid release requires $\mathrm{Ca}^{2+}$-assisted metabotropic glutamate receptor subtype 1 to phospholipase $\mathrm{C} \beta 4$ signaling cascade in the cerebellum. J Neurosci 25:6826-6835.

Matsui M, Yamada S, Oki T, Manabe T, Taketo MM, Ehlert FJ (2004) Functional analysis of muscarinic acetylcholine receptors using knockout mice. Life Sci 75:2971-2981.

Melis M, Perra S, Muntoni AL, Pillolla G, Lutz B, Marsicano G, Di Marzo V, Gessa GL, Pistis M (2004) Prefrontal cortex stimulation induces 2-arachidonoyl-glycerol-mediated suppression of excitation in dopamine neurons. J Neurosci 24:10707-10715.

Miura E, Fukaya M, Sato T, Sugihara K, Asano M, Yoshioka K, Watanabe M (2006) Expression and distribution of JNK/SAPK-associated scaffold protein JSAP1 in developing and adult mouse brain. J Neurochem 97:1431-1446.

Nakamura M, Sato K, Fukaya M, Araishi K, Aiba A, Kano M, Watanabe M (2004) Signaling complex formation of phospholipase C $\beta 4$ with metabotropic glutamate receptor type 1a and 1,4,5-trisphosphate receptor at the perisynapse and endoplasmic reticulum in the mouse brain. Eur J Neurosci 20:2929-2944.

Narushima M, Hashimoto K, Kano M (2006a) Endocannabinoid-mediated short-term suppression of excitatory synaptic transmission to medium spiny neurons in the striatum. Neurosci Res 54:159-164.

Narushima M, Uchigashima M, Hashimoto K, Watanabe M, Kano M (2006b) Depolarization-induced suppression of inhibition mediated by endocannabinoids at synapses from fast-spiking interneurons to medium spiny neurons in the striatum. Eur J Neurosci 24:2246-2252.

Ohno-Shosaku T, Maejima T, Kano M (2001) Endogenous cannabinoids mediate retrograde signals from depolarized postsynaptic neurons to presynaptic terminals. Neuron 29:729-738.

Ohno-Shosaku T, Matsui M, Fukudome Y, Shosaku J, Tsubokawa H, Taketo MM, Manabe T, Kano M (2003) Postsynaptic M1 and M3 receptors are responsible for the muscarinic enhancement of retrograde endocannabinoid signalling in the hippocampus. Eur J Neurosci 18:109-116.

Olson PA, Tkatch T, Hernandez-Lopez S, Ulrich S, Ilijic E, Mugnaini E, Zhang H, Bezprozvanny I, Surmeier DJ (2005) G-protein-coupled re- ceptor modulation of striatal $\mathrm{Ca}_{\mathrm{V}} 1.3 \mathrm{~L}$-type $\mathrm{Ca}^{2+}$ channels is dependent on a Shank-binding domain. J Neurosci 25:1050-1062.

Piomelli D (2003) The molecular logic of endocannabinoid signalling. Nat Rev Neurosci 4:873-884.

Plenz D (2003) When inhibition goes incognito: feedback interaction between spiny projection neurons in striatal function. Trends Neurosci 26:436-443.

Reynolds JN, Hyland BI, Wickens JR (2004) Modulation of an afterhyperpolarization by the substantia nigra induces pauses in the tonic firing of striatal cholinergic interneurons. J Neurosci 24:9870-9877.

Romero J, Lastres-Becker I, de Miguel R, Berrendero F, Ramos JA, FernandezRuiz J (2002) The endogenous cannabinoid system and the basal ganglia. Biochemical, pharmacological, and therapeutic aspects. Pharmacol Ther 95:137-152.

Shen W, Hamilton SE, Nathanson NM, Surmeier DJ (2005) Cholinergic suppression of KCNQ channel currents enhances excitability of striatal medium spiny neurons. J Neurosci 25:7449-7458.

Steiner H, Bonner TI, Zimmer AM, Kitai ST, Zimmer A (1999) Altered gene expression in striatal projection neurons in $\mathrm{CB} 1$ cannabinoid receptor knockout mice. Proc Natl Acad Sci USA 96:5786-5790.

Szabo B, Dorner L, Pfreundtner C, Norenberg W, Starke K (1998) Inhibition of GABAergic inhibitory postsynaptic currents by cannabinoids in rat corpus striatum. Neuroscience 85:395-403.

Tepper JM, Koos T, Wilson CJ (2004) GABAergic microcircuits in the neostriatum. Trends Neurosci 27:662-669.

Wang Z, Kai L, Day M, Ronesi J, Yin HH, Ding J, Tkatch T, Lovinger DM, Surmeier DJ (2006) Dopaminergic control of corticostriatal long-term synaptic depression in medium spiny neurons is mediated by cholinergic interneurons. Neuron 50:443-452.

Wilson CJ (2004) Basal ganglia. In: The synaptic organization of the brain, Ed 5 (Shepherd GM, ed), pp 361-413. Oxford: Oxford UP.

Wilson CJ, Chang HT, Kitai ST (1990) Firing patterns and synaptic potentials of identified giant aspiny interneurons in the rat neostriatum. J Neurosci 10:508-519.

Wilson RI, Nicoll RA (2001) Endogenous cannabinoids mediate retrograde signalling at hippocampal synapses. Nature 410:588-592.

Yan Z, Flores-Hernandez J, Surmeier DJ (2001) Coordinated expression of muscarinic receptor messenger RNAs in striatal medium spiny neurons. Neuroscience 103:1017-1024.

Zimmer A, Zimmer AM, Hohmann AG, Herkenham M, Bonner TI (1999) Increased mortality, hypoactivity, and hypoalgesia in cannabinoid CB1 receptor knockout mice. Proc Natl Acad Sci USA 96:5780-5785. 